\title{
Valor nutritivo da silagem de cana-de-açúcar tratada com uréia e acrescida de rolão-de-milho(1)
}

\begin{abstract}
João Batista de Andrade ${ }^{(2)}$, Evaldo Ferrari Júnior ${ }^{(2)}$ e Gilberto Braun ${ }^{(3)}$
Resumo - O objetivo deste trabalho foi determinar o valor nutritivo da silagem de cana-de-açúcar tratada com $0,5 \%$ de uréia e acrescida de $0,40,80$ e $120 \mathrm{~kg}$ de rolão-de-milho/t de cana-de-açúcar picada e ensilada. $\mathrm{O}$ experimento foi desenvolvido no Instituto de Zootecnia, em Nova Odessa, SP, em delineamento de blocos completos ao acaso com quatro repetições. $\mathrm{O}$ teste de consumo e digestibilidade foi efetuado com ovelhas em gaiolas com coletor e separador de fezes e urina. O teste constou de três períodos de 10, 10 e 5 dias, que corresponderam, respectivamente, aos períodos de adaptação, controle do consumo e coleta. A adição de rolão-de-milho melhorou o padrão de fermentação das silagens. O consumo de matéria seca e fibra insolúvel em detergente neutro, os coeficientes de digestibilidade da matéria seca e fibra insolúvel em detergente neutro, bem como a ingestão de nutrientes digestíveis totais, aumentaram linearmente com a elevação dos níveis de rolão-de-milho adicionados. O valor nutritivo das silagens aumentou com a adição de rolão-de-milho.
\end{abstract}

Termos para indexação: produtos fermentados, digestibilidade, alimentação animal, ovinos.

\section{Nutritive value of sugarcane silage treated with urea and added ground corn ears}

\begin{abstract}
The objective of this work was to determine the nutritive value of the silage of sugarcane treated with $0.5 \%$ of urea plus $0,40,80$ and $120 \mathrm{~kg}$ of ground corn ears/ton of chopped sugarcane conserved as silage. The experiment was developed at Instituto de Zootecnia, in Nova Odessa, SP, Brazil, according to a randomized complete blocks design, with four replications. Intake and digestibility trials were made in 10,10 and 5 day periods, corresponding to adaptation, intake and collection periods, respectively, with female sheep. The addition of ground corn ears improved fermentation pattern of the silages. The silage nutritive value measured as dry matter and neutral detergent fiber intake, dry matter and neutral detergent fiber digestibility coefficients and total digestible nutrients intake increased linearly with levels of ground corn ears.
\end{abstract}

Index terms: fermented products, digestibility, animal feeding, sheep.

\section{Introdução}

O teor de matéria seca adequada do material a ser ensilado é um dos principais fatores para a obtenção de silagens com bom padrão de fermentação (Wieringa, 1958; Jackson \& Forbes, 1970; Andrade, 1995).

\footnotetext{
(1)Aceito para publicação em 7 de novembro de 2000. Financiado pela Fapesp.

(2)Secretaria de Agricultura e Abastecimento do Estado de São Paulo, Instituto de Zootecnia, Centro de Forragicultura e Pastagens, Caixa Postal 60, CEP 13460-000 Nova Odessa, SP E-mail: jbandrade@izsp.br, ferrari@izsp.br

(3) Secretaria de Agricultura e Abastecimento do Estado de São Paulo, Instituto de Zootecnia, Centro de Nutrição e Alimentação Animal
}

Do capim-elefante, que geralmente apresenta baixo teor de matéria seca e carboidratos solúveis, freqüentemente são obtidas silagens de bom padrão de fermentação (Boin, 1975; Silveira et al., 1979; Lavezzo, 1981; Henrique, 1990). Silveira et al. (1979) determinaram, em silagens confeccionadas com capim-elefante, cortado ao redor de 60 dias de crescimento, a seguinte variação na composição: ácido lático, de 4,80 a 6,86\%, ácido acético, de 2,05 a 3,94\%, ácido butírico, de 0,006 a $0,019 \%$ e $\mathrm{N}$ amoniacal, de 9,97 a $13,17 \%$, podendo essas silagens ser classificadas como de boa qualidade, segundo Nilsson \& Nilsson (1956), Toth et al. (1956) e Wieringa (1966).

A cana-de-açúcar tem atraído o interesse dos pecuaristas, mais pelo seu alto potencial de produ- 
ção do que pelo seu valor nutritivo, quando comparado principalmente com silagens de milho ou sorgo.

Na literatura são poucos os trabalhos sobre silagem de cana-de-açúcar. Silvestre et al. (1976) estudaram o uso de uréia ou amônia na ensilagem de cana-deaçúcar para a engorda de bovinos. Alvarez \& Preston (1976) determinaram, em silagens de cana-de-açúcar com adição de amônia/melaço e uréia/melaço, 7,53 e 4,80\% de ácido lático e 0,87 e 1,7\% de ácido acético na matéria seca, respectivamente. Alvarez et al. (1977) verificaram que o ganho diário de animais alimentados com cana-de-açúcar desintegrada acrescida de uréia e aditivo rico em amido aumentou, mas o consumo da silagem foi sempre menor que o da cana-de-açúcar desintegrada. Ainda nesse trabalho, os autores determinaram, na matéria seca de amostras das silagens de cana-de-açúcar com adição de amônia mais melaço, $6,89 \%$ de ácido lático e $1,7 \%$ de ácido acético.

Alcântara et al. (1989) avaliaram cana-de-açúcar desintegrada e ensilada com ou sem hidróxido de sódio. Verificaram que o consumo de matéria seca da cana-de-açúcar desintegrada de $53,5 \mathrm{~g} / \mathrm{kg}^{0,75}$ e o de matéria seca da cana-de-açúcar ensilada com adição de $\mathrm{NaOH}$ (solução de $40 \%$, na base de $3 \%$ do peso seco) de $64,5 \mathrm{~g} / \mathrm{kg}^{0,75}$ foram superiores ao determinado quanto à cana-de-açúcar ensilada sem adição de $\mathrm{NaOH}$, que foi de $42,5 \mathrm{~g} / \mathrm{kg}^{0,75}$. Observaram, após 30 dias de ensilagem, para a silagem da canade-açúcar sem $\mathrm{NaOH}$, o que segue: 3,7 de $\mathrm{pH}, 1,52 \%$ de ácido lático, $0,46 \%$ de ácido acético, $0,00 \%$ de ácido butírico e 1,45\% de etanol (na matéria seca da silagem), enquanto na silagem efetuada com a canade-açúcar tratada com $\mathrm{NaOH}$ foram verificados 4,3 de $\mathrm{pH}, 2,19 \%$ de ácido lático, $0,66 \%$ de ácido acético, $0,00 \%$ de ácido butírico, e $0,22 \%$ de etanol.

Por outro lado, o rolão-de-milho ou o fubá de milho são fontes de energia usualmente recomendadas para serem misturadas à forragem de cana-deaçúcar nos arraçoamentos em que se utiliza uréia como proteína bruta (Gomes \& Mello, 1985; Pastori et al., 1986).

O objetivo deste trabalho foi avaliar a qualidade e o valor nutritivo de silagem de cana-de-açúcar tratada com uréia e acrescida de rolão-de-milho.

\section{Material e Métodos}

O trabalho foi desenvolvido no Instituto de Zootecnia, em Nova Odessa, SP. A variedade de cana-de-açúcar uti- lizada no experimento foi IAC-82-2045, plantada em 1996. Em setembro de 1997, foi efetuada uma adubação de cobertura, aplicando-se $60 \mathrm{~kg} / \mathrm{ha}$ de $\mathrm{P}_{2} \mathrm{O}_{5}, 60 \mathrm{~kg} / \mathrm{ha}$ de N e $60 \mathrm{~kg} / \mathrm{ha}$ de $\mathrm{K}_{2} \mathrm{O}$, como superfosfato simples, sulfato de amônio e cloreto de potássio, respectivamente. As silagens foram preparadas quando a cana-de-açúcar completou um ano de desenvolvimento. Como silos experimentais foram utilizadas barricas de plástico com capacidade de $150 \mathrm{~L}$.

A cana-de-açúcar foi picada em ensiladora regulada para cortar a forragem em pedaços de aproximadamente $1 \mathrm{~cm}$ de comprimento. Na ensilagem, a cana-de-açúcar picada foi tratada com $0,5 \%$ de uréia $(0,5 \mathrm{~kg}$ de uréia diluído em $2 \mathrm{~L}$ de água) e em seguida misturada ao rolão-demilho (espiga de milho com palha e sabugo moídos), utilizando-se os níveis de $0,40,80$ e $120 \mathrm{~kg} / \mathrm{t}$ de cana-deaçúcar picada, e a compactação do material foi efetuada pisando-se sobre ele no interior da barrica.

As amostragens das silagens foram efetuadas quando o nível das silagens nas barricas atingiu $50 \%$ da sua capacidade. Cada amostra foi dividida em duas porções, sendo uma utilizada para extração do suco através de prensa hidráulica. No suco das silagens, que foi mantido congelado em freezer, foram determinados os ácidos acéticos, propiônico, butírico e lático, bem como a concentração de álcool etílico. Foi determinada, também, a porcentagem de $\mathrm{N}$ amoniacal, como porcentagem do $\mathrm{N}$ total. $\mathrm{O}$ pH foi determinado imediatamente após a extração do suco, por meio de potenciômetro. Os ácidos orgânicos e o $\mathrm{N}$ amoniacal foram determinados segundo as técnicas de Tosi (1973) e Boin (1975).

A outra porção da amostra de silagem foi colocada em estufa de ar forçado, regulada a $65^{\circ} \mathrm{C}$, para secagem até peso constante. Após esfriamento e pesagem, a amostra foi moída em moinho de facas, com peneira de $1 \mathrm{~mm}$ e devidamente acondicionada em saco de plástico. Foram determinadas as porcentagens de matéria seca, proteína bruta, fibra bruta, extrato etéreo, matéria mineral e fibra insolúvel em detergente neutro, conforme Goering \& Soest (1970) e Association of Official Agricultural Chemists (1975).

A prova de consumo voluntário e digestibilidade aparente foi efetuada com ovelhas, com peso médio ao redor de $35 \mathrm{~kg}$. Os animais foram vermifugados antes do início do ensaio. Durante o período experimental, os animais foram mantidos em gaiolas individuais com coletor e separador de fezes e urina. Além das silagens, os animais receberam sal mineral e água a vontade. A prova de consumo e digestibilidade foi efetuada pelo método de coleta total de fezes, em três períodos subseqüentes correspondentes a 10 dias de adaptação, 10 dias de controle de consumo e 5 dias de coleta. No período de coleta, os animais 
receberam a quantidade de silagem determinada como consumo voluntário. Nas amostras de fezes e sobras foram efetuadas as mesmas análises realizadas nas silagens.

Os animais foram agrupados em quatro blocos, de acordo com seus pesos. O delineamento utilizado foi o de blocos completos ao acaso, com quatro repetições, e a análise estatística, efetuada conforme Pimentel-Gomes (1970).

\section{Resultados e Discussão}

A análise de variância dos teores de matéria seca das silagens mostrou significância $(\mathrm{P}<0,05)$ quanto aos níveis de rolão-de-milho utilizados (Tabela 1). Os resultados da análise de regressão mostraram que o aumento dos teores de matéria seca ocorrido com a aplicação do rolão-de-milho na ensilagem pode ser descrita pela equação linear $\mathrm{y}=20,9285+0,0564 \mathrm{x}$ $\left(\mathrm{P}<0,05\right.$ e $\left.\mathrm{R}^{2}=0,8767\right)$. Essa elevação dos teores de matéria seca das silagens, embora esperada, deve melhorar o padrão de fermentação do material (Wieringa, 1958; Lavezzo, 1981; Andrade, 1995).

O resultado da análise de variância dos teores de proteína bruta das silagens mostrou que não houve significância $(\mathrm{P}>0,05)$ quanto aos níveis estudados. Porém, a análise de regressão mostrou que a variação dos teores de proteína bruta das silagens pode ser descrita pela equação quadrática $\mathrm{y}=9,4309$ $0,0166 \mathrm{x}+0,001 \mathrm{x}^{2}\left(\mathrm{P}<0,05\right.$ e $\left.\mathrm{R}^{2}=0,9606\right)$. Os resultados mostraram pequena variação, e todas as silagens apresentaram teores superiores a $8 \%$, valor este relatado por Minson (1971) como sendo o teor mínimo para promover bom consumo de forragem.

Quanto aos teores de fibra insolúvel em detergente neutro das silagens, a análise de variância mostrou significância $(\mathrm{P}<0,05)$ dos níveis utilizados. Também a análise de regressão mostrou que a varia-

Tabela 1. Porcentagens de matéria seca (MS), proteína bruta (PB) e fibra insolúvel em detergente neutro (FDN) das silagens de cana-de-açúcar tratada com uréia e acrescida de rolão-de-milho ${ }^{(1)}$

\begin{tabular}{lccc}
\hline Silagem & MS & PB & FDN \\
\hline Cana + uréia & 20,93 & 9,43 & 68,70 \\
Cana + uréia + 40 kg de rolão & 23,18 & 9,03 & 66,20 \\
Cana + uréia + 80 kg de rolão & 25,44 & 9,18 & 63,71 \\
Cana + uréia + 120 kg de rolão & 27,69 & 9,86 & 61,21 \\
\hline CV $(\%)$ & 4,55 & 4,96 & 2,63 \\
\hline
\end{tabular}

(1)Quilograma de rolão-de-milho/t de cana-de-açúcar. ção desses teores pode ser descrita pela equação linear $\mathrm{y}=68,7020-0,0624 \mathrm{x}\left(\mathrm{P}<0,05\right.$ e $\left.\mathrm{R}^{2}=0,7457\right)$. Essa redução pode ser explicada pela adição de rolãode-milho.

Não foram observadas diferenças entre os valores de $\mathrm{pH}(\mathrm{P}>0,05)$ (Tabela 2). No entanto, a análise de regressão mostrou que a variação destes pode ser representada pela equação quadrática $\mathrm{y}=3,4910$ $0,0024 x+0,00002 x^{2}\left(P<0,05\right.$ e $\left.R^{2}=0,8375\right)$. Os valores de $\mathrm{pH}$ das silagens foram próximos dos observados por Alcântara et al. (1989), e mostraram pequena variação, podendo as silagens ser classificadas como de boa qualidade, conforme Nilsson \& Nilsson (1956), Toth et al. (1956) e Wieringa (1966).

Quando foram analisados os teores de álcool etílico das silagens, foi observada significância $(\mathrm{P}<0,05)$ entre tratamentos, e a análise de regressão mostrou que a variação dos teores de álcool etílico pode ser descrita pela equação linear $\mathrm{y}=12,8560$ 0,1066x ( $\mathrm{P}<0,05$ e $\left.\mathrm{R}^{2}=0,9437\right)$ (Tabela 2). Houve uma redução na produção de etanol à medida que níveis mais altos de rolão-de-milho foram aplicados na ensilagem, mostrando que o aumento do teor de matéria seca limita a produção de etanol. Assim, tanto o aumento no teor de matéria seca como a redução na produção de etanol foi de $99,46 \%$, quando comparados os níveis de 0 e $120 \mathrm{~kg}$ de rolão-de-milho/t de cana-de-açúcar. Esse fato pode propiciar maior consumo de matéria seca, conforme dados de Jackson \& Forbes (1970), Alcântara et al. (1989) e Andrade (1995).

Embora a análise de variância não tenha mostrado significância $(\mathrm{P}>0,05)$ entre tratamentos, a análise de regressão revelou que a variação dos teores de ácido acético nas silagens pode ser descrita pela equação linear $\mathrm{y}=0,9122+0,0102 x(\mathrm{P}<0,05 \mathrm{e}$ $\left.\mathrm{R}^{2}=0,7557\right)$ (Tabela 2 ). Houve um aumento na produção de ácido acético à medida que foi elevado o nível de rolão-de-milho na ensilagem da cana-deaçúcar. Essa resposta está de acordo com a encontrada por Wieringa (1958), que constatou que as bactérias heterofermentativas são mais tolerantes à elevação do potencial osmótico das silagens. Os teores de ácido acético encontrados nas silagens são próximos dos citados por Alvarez \& Preston (1976) e Alvarez et al. (1977), e podem reduzir o consumo dessas silagens (Boin, 1975; Silveira et al., 1979; Lavezzo, 
1981). Apesar disso, as silagens ainda podem ser classificadas como de boa qualidade, pelas classificações de Nilsson \& Nilsson (1956), Toth et al. (1956) e Wieringa (1966).

Nas amostras de silagens, não foi detectada a presença de ácido butírico, e os teores de ácido propiônico foram, em todas as silagens, muito baixos, da ordem de $0,04 \%$ na matéria seca (Tabela 2). A ausência de ácido butírico e os baixos teores de ácido propiônico permitem classificar as silagens como de boa qualidade, conforme os critérios de Nilsson \& Nilsson (1956), Toth et al. (1956) e Wieringa (1966).

A análise de variância entre os teores de ácido lático das silagens mostrou que não houve significância $(\mathrm{P}>0,05)$ entre tratamentos, e a análise de regressão mostrou que a variação nos teores de ácido lático não pode ser descrita por nenhuma das curvas estudadas (Tabela 2). A produção de ácido lático foi menor que a observada quanto à silagem de cana-de-açúcar sem aditivo nos ensaios de Alvarez \& Preston (1976) e Alcântara et al. (1989) e quanto às silagens de capim-elefante estudadas por Silveira et al. (1979).

Quanto às porcentagens de $\mathrm{N}$ amoniacal, medidas como porcentagem do $\mathrm{N}$ total da amostra, a análise de variância mostrou que não houve significância $(\mathrm{P}<0,05)$ entre tratamentos, e pela análise de regressão foi observado que a variação ocorrida nos teores de $\mathrm{N}$ amoniacal não pôde ser representada por nenhuma das curvas estudadas, ou seja, linear, quadrática e cúbica (Tabela 2). Quanto aos valores observados, são considerados baixos, principalmente levando-se em conta a aplicação de uréia no momento da ensilagem (Silveira et al., 1979; Lavezzo,
1981; Andrade, 1995). Todas as silagens, pelos teores de $\mathrm{N}$ amoniacal, podem ser classificadas como de boa qualidade, segundo os critérios de Nilsson \& Nilsson (1956), Toth et al. (1956) e Wieringa (1966).

O resultado da análise de variância dos consumos de matéria seca mostrou significância $(\mathrm{P}<0,05)$ entre tratamentos (Tabela 2). Também a análise de regressão nos permite afirmar que houve um aumento da ingestão de matéria seca com a elevação dos níveis de rolão-de-milho, e que a variação pode ser descrita pela equação linear $y=26,4720+0,1683 x$ $\left(\mathrm{P}<0,05\right.$ e $\left.\mathrm{R}^{2}=0,8811\right)$. Esse resultado está de acordo com o observado por Jackson \& Forbes (1970), que encontraram maior consumo das silagens com maiores teores de matéria seca. Também, o aumento de rolão-de-milho pode ter elevado o consumo das silagens (Gomes \& Mello, 1985; Pastori et al., 1986).

No que diz respeito aos consumos de fibra insolúvel em detergente neutro, a análise de variância mostrou que houve significância $(\mathrm{P}<0,05)$, e pela análise de regressão pode-se verificar que houve aumento linear do consumo de fibra insolúvel em detergente neutro à medida que foi utilizado maior nível de rolão-de-milho na cana-de-açúcar $\left(\mathrm{y}=17,7427+0,0885 \mathrm{x}(\mathrm{P}<0,05)\right.$ e $\left.\mathrm{R}^{2}=0,9157\right)$ (Tabela 3). Estes resultados mostraram que os animais não atingiram o consumo máximo do alimento, uma vez que nesse consumo a ingestão de fibra insolúvel em detergente neutro é praticamente constante, conforme dados de Resende et al. (1994). Se o consumo não foi máximo, então este não foi limitado pelo enchimento do espaço físico do trato gastrintestinal, podendo, talvez, ter sido limitado por algum produto do metabolismo dos carboidratos solúveis.

Tabela 2. Índices de $\mathrm{pH}$, porcentagens de álcool etílico (AE), ácido acético (AA), ácido lático (AL) e nitrogênio amoniacal (NA) na matéria seca das silagens de cana-de-açúcar tratada com uréia e acrescida de rolão-de-milho( ${ }^{(1)}$.

\begin{tabular}{lccccc}
\hline Silagem & $\mathrm{pH}$ & $\mathrm{AE}$ & $\mathrm{AA}$ & $\mathrm{AL}$ & $\mathrm{NA}^{(2)}$ \\
& & $-12,86$ & 0,91 & 4,14 & 14,82 \\
Cana + uréía & 3,49 & 8,59 & 1,32 & 4,62 & 14,82 \\
Cana + uréia + 40 kg de rolão & 3,43 & 4,33 & 1,66 & 4,78 & 13,62 \\
Cana + uréia + 80 kg de rolão & 3,41 & 0,07 & 2,21 & 3,67 & 14,54 \\
Cana + uréia + 120 kg de rolão & 3,46 & 27,08 & 45,28 & 22,81 & 18,97 \\
\hline CV $(\%)$ & 1,40 & &
\end{tabular}

${ }^{(1)}$ Quilograma de rolão-de-milho/t de cana-de-açúcar. ${ }^{(2)}$ Porcentagem do nitrogênio total da amostra. 
Tabela 3. Consumo médio de matéria seca (CMS) e fibra insolúvel em detergente neutro (CFDN), coeficiente de digestibilidade médio da matéria seca (CDMS) e da fibra insolúvel em detergente neutro (CDFDN), e consumo médio de nutrientes digestíveis totais (CNDT) das silagens de cana-de-açúcar tratada com uréia e acrescida de rolão-de-milho ${ }^{(1)}$.

\begin{tabular}{lccccc}
\hline Silagem & $\begin{array}{c}\text { CMS } \\
\left({\mathrm{g} / \mathrm{kg}^{0,75}}^{0}\right.\end{array}$ & $\begin{array}{c}\text { CFDN } \\
\left(\mathrm{g}^{\mathrm{kg}}{ }^{0,75}\right)\end{array}$ & $\begin{array}{c}\text { CDMS } \\
(\%)\end{array}$ & $\begin{array}{c}\text { CDFDN } \\
(\%)\end{array}$ & $\begin{array}{c}\text { CNDT } \\
\left(\mathrm{g} / \mathrm{kg}^{0,75}\right)\end{array}$ \\
\hline Cana + uréia & 26,47 & 17,22 & 53,64 & 43,90 & 14,08 \\
Cana + uréia + 40 kg de rolão & 33,20 & 21,28 & 57,06 & 47,15 & 19,57 \\
Cana + uréia + 80 kg de rolão & 39,93 & 24,83 & 60,47 & 50,50 & 25,06 \\
Cana + uréia + 120 kg de rolão & 46,77 & 28,37 & 63,88 & 53,86 & 30,55 \\
\hline CV $(\%)$ & 19,52 & 20,61 & 8,84 & 13,71 & 23,88 \\
\hline
\end{tabular}

${ }^{(1)}$ Quilograma de rolão-de-milho/t de cana-de-açúcar.

$\mathrm{Na}$ análise de variância dos coeficientes de digestibilidade da matéria seca, não foi encontrada significância $(\mathrm{P}>0,05)$ para níveis (Tabela 3). Porém, $\mathrm{a}$ análise de regressão mostrou que os coeficientes aumentaram linearmente com a elevação dos níveis de rolão-de-milho na cana-de-açúcar ensilada e que o aumento pode ser descrito pela equação $\mathrm{y}=53,6437+0,0853 \mathrm{x}\left(\mathrm{P}<0,05\right.$ e $\left.\mathrm{R}^{2}=0,9982\right)$. Esse resultado já era esperado, uma vez que o rolão-demilho é altamente digestível e proporciona maior desempenho (Silvestre et al., 1976).

O resultado da análise de variância dos coeficientes de digestibilidade da fibra insolúvel em detergente neutro mostrou que não houve significância $(\mathrm{P}>0,05)$ (Tabela 3). Porém, pela análise de regressão, verifica-se que houve um aumento do coeficiente à medida que houve aumento dos níveis de rolão-de-milho na cana-de-açúcar ensilada, podendo a variação ser descrita pela equação y $=43,7920+0,0839 x(\mathrm{P}<0,05$ e $\left.\mathrm{R}^{2}=0,7598\right)$. Os valores obtidos, mesmo em silagens de cana, apontam que a fibra da cana-deaçúcar é de baixa utilização e que esta não é importante como determinante do valor nutritivo (Boin et al., 1987).

Quanto aos consumos de nutrientes digestíveis totais, o resultado da análise de variância mostrou que houve significância $(\mathrm{P}<0,05)$ entre tratamentos (Tabela 3). Também, pela análise de regressão, verifica-se que houve aumento linear da ingestão de nutrientes digestíveis totais, e que essa variação pode ser representada pela equação $\mathrm{y}=14,0865+0,1372 \mathrm{x}$ $\left(\mathrm{P}<0,05\right.$ e $\left.\mathrm{R}^{2}=0,9426\right)$. Embora os animais não tivessem atingido o consumo máximo, esse resultado já era esperado, uma vez que houve aumentos lineares de ingestão e digestibilidade da matéria seca.

\section{Conclusões}

1. A adição de rolão-de-milho na ensilagem da cana-de-açúcar tratada com uréia melhora o padrão de fermentação da silagem.

2. A adição de rolão-de-milho na ensilagem de cana-de-açúcar tratada com uréia aumenta linearmente o valor nutritivo da silagem.

\section{Referências}

ALCÂNTARA, E.; AGUILERA, A.; ELLIOTT, R.; SHIMADA, A. Fermentation and utilization by lambs of sugarcane harvest fresh and ensiled with and without NaOH: 4. Ruminal kinetcs. Animal Feed Science and Technology, Amsterdam, v. 23, p. 323-331, 1989.

ALVAREZ, F. J.; PRESTON, T. R. Ammonia/molasses and urea/molasses as additives for ensiled sugar cane. Tropical Animal Production, Merida, v. 1, p. 98-104, 1976.

ALVAREZ, F. J.; PRIEGO, A.; PRESTON, T. R. Animal performance on ensiled sugar cane. Tropical Animal Production, Merida, v. 2, p. 27-33, 1977.

ANDRADE, J. B. Efeito da adição de rolão de milho, farelo de trigo e sacarina na ensilagem do capim-elefante (Pennisetum purpureum Schum.). Botucatu: Unesp, 1995. 190 p. Tese de Doutorado.

ASSOCIATION OF OFFICIAL AGRICULTURAL CHEMISTS (Gaithersburg, Estados Unidos). Official methods of analysis of the Association of Official Analytical Chemists.12. ed. Washington, 1975. 1015 p. 
BOIN, C. Elephant (napier) grass silage production: effect of addition on chemical composition, nutritive value and animal performance. Ithaca: Cornell University, 1975. 215 p. PhD. Thesis.

BOIN, C.; MATTOS, W. R. S.; D‘ ARCE, R. D. Cana-deaçúcar e seus subprodutos na alimentação de ruminantes. In: PARANHOS, S. B. (Coord.). Cana-de-açúcar: cultivo e utilização. Campinas: Fundação Cargill, 1987. v. 2, p. 805-850.

GOERING, H. K.; SOEST, P. J. van. Forage fiber analysis: apparatus, reagents, procedures, and some applications. Washington: USDA, 1970. 20 p. (Agricultural Handbook, 379).

GOMES, A. T.; MELLO, R. P. O sistema de produção implantado no CNPGL. 3. ed. Coronel Pacheco: Embrapa-CNPGL, 1985. 76 p. (Documentos, 1).

HENRIQUE, W. Efeito do uso de aditivos enzimobacterianos sobre a qualidade da silagem de capim-elefante (Pennisetum purpureum Schum.). Piracicaba: Esalq, 1990. 100 p. Dissertação de Mestrado.

JACKSON, N.; FORBES, T. T. The voluntary intake by cattle of four silages differing in dry matter content. Animal Production, Edinburgh, v. 12, p. 591- 599, 1970.

LAVEZZO, W. Efeito de diferentes métodos de tratamento, sobre a composição química e valor nutritivo das silagens de capim-elefante (Pennisetum purpureum Schum.). Botucatu: Unesp, 1981. 304 p. Tese de Livre Docência.

MINSON, D. J. The digestibility and voluntary intake of six varieties of Panicum. Australian Journal of Experimental Agriculture and Animal Husbandry, Melbourne, v. 11, n. 48, p. 18-25, 1971.

NILSSON, G.; NILSSON, P. E. The microflora on the surface of some fodder plants at different stages of maturity. Archives of Microbiology, Berlin, v. 24, n. 4, p. 412-422, 1956.
PASTORI, A. M.; ANDRADE, P.; SAMPAIO, A. A. M.; ROSA, L. C. A.; ANDRADE, A. T.; OLIVEIRA, M. D. S. Valor nutritivo de rações contendo cana-de-açúcar, camade-frango e milho. Pesquisa Agropecuária Brasileira, Brasília, v. 21, n. 2, p. 211-214, fev. 1986.

PIMENTEL-GOMES, F. Curso de Estatística Experimental. 4. ed. São Paulo: Nobel, 1970. 368 p.

RESENDE, F. D.; QUEIROZ, A. C.; FONTES, C. A. A.; RODRIGUEZ, R. R.; FREITAS, J. A.; SOARES, J. E.; JORGE, A. M. Rações com diferentes níveis de fibra em detergente neutro na alimentação de bovídeos em confinamento. Revista da Sociedade Brasileira de Zootecnia, Viçosa, MG, v. 23, n. 3, p. 366-376, 1994.

SILVEIRA, A. C.; LAVEZZO, W.; TOSI, H.; GONÇALVES, D. A. Avaliação química de silagens de capim-elefante (Pennisetum purpureum Schum.) submetidas a diferentes tratamentos. Revista da Sociedade Brasileira de Zootecnia, Viçosa, MG, v. 8, n. 2, p. 287-300, 1979.

SILVESTRE, R.; MacLEOD, N. A.; PRESTON, T. R. Sugar cane ensiled with urea or ammonia for fattening cattle. Tropical Animal Production, Merida, v. 1, p. 216-222, 1976.

TOSI, H. Ensilagem de gramíneas tropicais sob diferentes tratamentos. Botucatu: Faculdade de Ciências Médicas e Biológicas, 1973. 107 p. Tese de Doutorado.

TOTH, I.; RVDIN, C.; NILSSON, R. Study on fermentation processes in silage: comparison of different types of forage crops. Archives of Microbiology, Berlin, v. 25 , n. 2, p. 208-218, 1956.

WIERINGA, G. W. The effect of wilting on butyric acid fermentation in silage. Netherlands Journal of Agricultural Science, Wageningen, v. 6, n. 3, p. 204-210, 1958.

WIERINGA, G. W. The influence of nitrate on silage fermentation. In: INTERNATIONAL GRASSLAND CONGRESS, 10., 1966, Helsinki. Proceedings... Helsinki: University of Helsinki, 1966. p. 537-540. 